University of Nebraska - Lincoln

DigitalCommons@University of Nebraska - Lincoln

Sociology Department, Faculty Publications

Sociology, Department of

$10-1-2006$

\title{
A Qualitative Study of Early Family Histories and Transitions of Homeless Youth
}

Kimberly A. Tyler

University of Nebraska-Lincoln, kim@ktresearch.net

Follow this and additional works at: https://digitalcommons.unl.edu/sociologyfacpub

Part of the Sociology Commons

Tyler, Kimberly A., "A Qualitative Study of Early Family Histories and Transitions of Homeless Youth" (2006). Sociology Department, Faculty Publications. 68.

https://digitalcommons.unl.edu/sociologyfacpub/68

This Article is brought to you for free and open access by the Sociology, Department of at DigitalCommons@University of Nebraska - Lincoln. It has been accepted for inclusion in Sociology Department, Faculty Publications by an authorized administrator of DigitalCommons@University of Nebraska - Lincoln. 


\title{
A Qualitative Study of Early Family Histories and Transitions of Homeless Youth
}

\author{
Kimberly A. Tyler \\ University of Nebraska-Lincoln
}

\begin{abstract}
Using intensive qualitative interviews with 40 homeless youth, this study examined their early family histories for abuse, neglect, and other family problems and the number and types of transitions that youth experienced. Multiple forms of child maltreatment, family alcoholism, drug use, and criminal activity characterized early family histories of many youth. Leaving home because of either running away or being removed by child protective services often resulted in multiple transitions, which regularly included moving from foster care homes to a group home, back to their parents, and then again returning to the streets. Although having experienced family disorganization set youth on trajectories for early independence, there were many unique paths that youth traveled prior to ending up on the streets.
\end{abstract}

Keywords: child maltreatment, family histories, homeless youth

$\mathrm{V}$ iolence and abuse are common themes in the backgrounds of numerous homeless youth. Many studies have found that at least 33\% of homeless youth have suffered from sexual abuse (McCormack, Janus, \& Burgess, 1986; Tyler, Hoyt, \& Whitbeck, 2000) and more than 50\% have experienced physical abuse and/or neglect (Powers, Eckenrode, \& Jaklitsch, 1990; Tyler \& Cauce, 2002). In addition, young people who have experienced physical and/or sexual abuse are at higher risk for running away (Janus, Archambault, Brown, \& Welsh, 1995). Parental substance abuse also is a common experience among homeless and runaway youth (Fors \& Rojek, 1991; Ginzler, Cochran, Domenech-Rodriguez, Cauce, \&

This research was funded by a UNL Faculty Seed Grant awarded to the author and by the National Institute of Mental Health (MH 57110). 
Whitbeck, 2003) and has been found to be associated with both physical and sexual abuse (Whitbeck \& Hoyt, 1999). Moreover, research finds that youth who have family members with substance misuse problems are more likely to use alcohol and other substances (Ary, Tildesley, Hops, \& Andrews, 1993; Kandel \& Andrews, 1987) and are more likely to develop an alcohol or drug use problem themselves (Anderson \& Henry, 1994; Brown, Tate, Vik, Haas, \& Aarons, 1999).

Although having experienced family disorganization is likely to set youth on trajectories for early independence, the paths they wind up on may vary significantly depending on their specific family histories. Little is known, however, about the types of transitions that youth experience after they run from abusive homes. As such, the purpose of the current study was to (a) examine young people's histories for abuse, neglect, and other family problems and (b) examine the number and types of transitions that young people have experienced based on in-depth, qualitative interviews with 40 homeless youth.

\section{Theoretical Explanation}

According to life course perspective (Elder, 1998), early family interaction patterns create blueprints for later living. That is, given that many homeless youth have family histories characterized by abuse and parental substance misuse, they are likely to learn interaction styles at home that are coercive and controlling. The interaction styles that youth learn early on become reinforcing and result in the selection and creation of new environments that are familiar and congruent with past interaction styles (Caspi, Bem, \& Elder, 1987). In addition, the family backgrounds of these young people are associated with the timing of events, which in turn influences the types of trajectories that these youth experience. Although some youth may experience few transitions, others will undoubtedly have pathways that are more disruptive, which may set in motion a trajectory characterized by instability and multiple transitions and may have lifelong repercussions for these youth as they make the transition to young adulthood.

\section{Method}

This investigation is based on data obtained from semistructured interviews with 40 homeless youth (16 males, 24 females). The majority $(n=27)$ were European American. Young people were interviewed in 
four Midwestern states (Missouri, Iowa, Nebraska, and Kansas) by fulltime street interviewers. Interviews were conducted in shelter interview rooms, quiet corners of restaurants, and libraries. Study eligibility required young people to be between 19 and 21 years of age and homeless. The definition of homeless mandated that the youth currently reside in a shelter, on the street, or independently (e.g., with friends) because they had run away, had been pushed out, or had drifted out of their family of origin. Study procedures were explained, and informed consent was obtained from youth.

All interviews were audiotaped and lasted 1 to 1.5 hours. Participants were asked a series of open-ended questions that focused on maltreatment, parents' substance use, criminal activity, and all prior living situations up to the time of their interview. Based on interviewer reports, approximately $95 \%$ of young people who were approached for an interview and who met study criteria agreed to participate in the study. Each interview was transcribed verbatim. To preserve confidentiality, all names of respondents have been changed. Respondents were paid \$25 for the interview.

After the interviews were transcribed, each interview was carefully read through, and each incident of child abuse was coded as sexual abuse, physical abuse, neglect, or verbal abuse. Similar coding was also done for incidences of parental substance misuse, criminal activity, and domestic violence. Finally, each transition that youth experienced (e.g., foster care, detention, group home, ran away) was coded. During this process of open- ended coding, two major themes emerged: (a) family disorganization and (b) child transitions. After these two broad themes were identified, the process of focused coding began (Charmaz, 1995), which included searching the coded interviews for particularly telling excerpts and grouping them according to theme.

\section{Findings}

\section{Family Disorganization}

Parental substance misuse. Alcohol use and/or drug use characterized the majority of households $(n=37)$. As two youth explained, "My dad and my mom both drink really hard. Uh my dad smoked pot for a really long time, ate mushrooms for a long time.... My mom smokes pot ... and then she drank like two, three times a week." "My dad used to drink and do drugs on a daily basis. My mom ... still drinks; she's a very big [alcoholic], and she's still a drug addict." 
Not only were many of their parents involved with substance use but, for some youth, this pattern was characteristic of their wider family network. According to Michelle, "Um on my dad's side there's alcohol. My grandfather died from alcohol abuse.... My dad's three brothers are all alcoholics and do drugs." Similarly, Jennifer added, "My dad when he was younger used to be a real bad [alcoholic] and a drug dealer and then all my cousins, they're all drug dealers and into that kind of stuff." Because research finds that youth are more likely to use alcohol and other substances if family members are using (Ary et al., 1993) and that children who have parents with alcohol problems are more likely to develop an alcohol or drug use problem (Anderson \& Henry, 1994; Brown et al., 1999), the family histories of these young people suggest that many youth may be at risk for experiencing substance abuse problems themselves.

Criminal activity. Parents' criminal activity, which included being arrested for child abuse, domestic violence, and drug use, was also widespread in some families. When asked about criminal activity, Jordan replied, "My dad has been caught drugged and drunk a couple of times. So you know DWIs and gets his license taken away." According to Vanessa, "My mom went to the pen like two different times for selling [crack] to an undercover cop." Sandra reported, "My dad has been arrested for like domestic...on me and my mom." Continuous exposure to criminal activity may send the message to young people that this type of behavior is acceptable, and they may be at risk for modeling their parents' behavior, thus potentially affecting their future life trajectories. In some cases, excessive alcohol was associated with caretakers being abusive and physically violent. Michelle recalled, "I left home because my father was an alcoholic, and he's abusive and he has mental problems. It [the abuse] happened every Friday, Saturday, and Sunday night; every time he was drinking." Mandy responded, "Dad is an alcoholic and gets abusiveboth physical and sexual abuse." The responses from these young people suggest that substance use was a precursor (although perhaps not the only one) to violence in the home.

Child maltreatment. The majority of the sample experienced some form of child maltreatment, and some youth experienced as many as three or four. One female respondent reported: "I've always been abused. I've been abused ever since I was little. That's one of the reasons why I went into the state's custody was because I was mentally, physically, emotionally, [and] sexually abused."

By far, physical abuse, reported by the majority of young people $(n=$ 36 ), was the most common form of maltreatment. Many young women 
shared vivid accounts of being pushed down stairs, having their hair pulled out, and being hit in the head on several occasions. Male youth also reported similar physical abuse experiences perpetrated by their parents, which included being hit with numerous objects. For example, "My mom used to spank me a lot. Hit me with [a] belt, shoe, dog food cans, pretty much what she could get her hands on. This happened as long as I can remember."

The majority of youth have experienced and/or witnessed physical abuse. It was also apparent (based on youth reports) that some of their mothers who were victims of domestic violence felt helpless and were unable to protect their children. Sandra explained, "My mom was there when he [dad] was doing it but she was so scared of him. He had already beat her and he needed some[one] else so he picked me, and my mom was right there watching." This quote indicates that violence is extremely prevalent in some households, and youth and other family members are at risk.

Another form of child maltreatment that some young people reported experiencing was sexual abuse. One male reports, "[I] was sexually abused by my father. I remember when I was sleeping and he [father] was messing around with me. And when my sister was taking a bath, he went in there messing around with her." Although a couple of males reported being sexually abused, the majority of sexual abuse victims were female. One young woman summarized her experience of sexual abuse: "I was 12, almost 13, it [sexual abuse] happened for a whole summer; every night after he got off work. And sometimes during the day my mom would leave and go somewhere then he'd do it [sexually abuse me]." This was a common experience for $13(33 \%)$ of the young people.

Other types of maltreatment included verbal abuse and neglect. Severe cases of child neglect were recalled by a few of the young women:

My mom was charged with three counts of neglect. Like sticking me in a closet and not giving me any food and putting like an open bottle of bleach in the little closet so that it would stink and I would end up barfing and puking.

Candy reported similar experiences, and even on removal from her home, she also reported feeling neglected in foster care, suggesting that removing youth from their parents' custody does not automatically ensure a safeguard because some young people continued to be neglected and/or abused by foster parents or other legal guardians.

Many of these young people have been exposed to domestic violence and have experienced physical abuse, both of which can have negative outcomes for their well-being. The physical abuse and assault they ex- 
perience and/or witness may be internalized and become part of their interaction styles, which increases their chances of associating with others who are also violent or becoming violent themselves. The sexual abuse that they have experienced will likely increase some youths' chances of being revictimized. That is, homeless youth who experience early sexual abuse are more likely to experience sexual victimization on the street. This path has been found to be direct and indirect via delinquent involvement (e.g., conning) and trading sex (Tyler et al., 2000; Tyler, Hoyt, Whitbeck, \& Cauce, 2001). In the end, the majority dealt with the abuse by running away, although in many cases, abuse was not the sole reason for running; more widespread family disorganization (i.e., parents' substance abuse and/or mental health problems) was also present.

\section{Child Transitions}

Running away. Many respondents experienced multiple transitions beginning at an early age. Jordan and Michelle, for example, ran away from home for the first time at 16 and 13, respectively. Both youths had a biological alcoholic father and other family members who used drugs. Michelle indicated that her father had mental health problems, and both young people were physically abused, which is the most important reason for why they ran away (although it was not the only reason). Jordan experienced 13 transitions (e.g., staying at a youth center, group home, girlfriend's apartment, on the street) within approximately a 2-year period after initially running away because of early abuse.

Cindy was "pushed out" of home and has also experienced numerous hardships both prior to leaving home and since she has been on her own. The death of Cindy's parents and then later her grandparents led to numerous living situations for Cindy, where she eventually wound up in a drug rehabilitation program. Cindy returned to her aunt's home but that did not work out, and she was once again forced to leave. Even though she did not initially run away, Cindy's family history placed her on a trajectory for early independence at a young age. Since then, she has experienced multiple transitions and major disruptions along the way.

Foster care. Other youth went through multiple transitions not because they had run away but because they had been removed from parental custody because of abuse, neglect, and/or abandonment and placed in a series of foster homes. Vanessa and her siblings, for example, were removed from their home by the state because their mother abused drugs and abandoned Vanessa and her siblings. Vanessa was later ad- 
opted but was very unhappy with her living situation and continued to run away. Jackie, who was removed from her home by the state, experienced an inordinate number of transitions including numerous placements in foster care.

Children placed in foster homes are at extreme risk for a wide range of disorders and adjustment problems during the life course, such as substance abuse and educational failure. It is estimated that $50 \%$ to more than $80 \%$ of children in foster care have developmental and mental health problems (Garland et al., 2000). Therefore, the young people in this study who have experienced multiple placements are at risk for serious outcomes.

Detention. Spending time in detention facilities was another pathway that some young people experienced prior to becoming homeless. Brian, for example, reported running away because his parents were constantly fighting and he detested his stepfather. Brian ran away from his parents' home several times before going to a detention facility, but he also experienced additional transitions along the way.

Cindy, Jackie, Brian, Vanessa, and many other youth in the current study have similar histories in terms of multiple transitions. For the most part, the life histories of these youth are highly nomadic and have average stays in one location of 3 months or less. Although the actual number of transitions varies from person to person, their stories are similar: family disorganization, remarkably unstable lives, and unique trajectories, all of which are tied to their early family histories.

\section{Discussion}

This study explored early family histories of homeless youth and the multiple transitions that they have experienced as a result. Parental alcohol and drug use, criminal activity, domestic violence, and various forms of child maltreatment characterized their families. Whether they were removed from their home or whether they made the decision to leave, an environment of conflict, abuse, and/or violence placed youth on early trajectories that subsequently resulted in numerous transitions. The number of transitions that many of these young people described was remarkable. Some youth could not recall the exact number of moves, especially in cases in which foster care placements numbered five or more. Although being placed in multiple foster homes is stressful in and of itself for the child, the risks and outcomes associated with foster care placement in general are grave (Garland et al., 2000). 
Understanding the early life histories of homeless and runaway youth is crucial because it helps to explain how they arrived at their current situation. Consistent with a life course perspective (Elder, 1998), young people who grow up in physically violent and troubled families are likely to learn similar interaction styles. These negative interaction styles become self-reinforcing over time, resulting in the selection and creation of new environments that are familiar and congruent with past ones (Caspi et al., 1987). In addition, early instability, such as running away or placement in alternative care, may have lifelong repercussions for these youth as they make the transition to young adulthood.

The nomadic nature of their lives thus far suggests that they have accumulated few resources along the way. Many have not completed high school, very few are employed full-time, and many have relationships that are unstable, all of which will likely affect them later in life. However, interventions that provide these youth with basic life skills, education and employment training, and programs to improve their self-esteem and self-worth may place them in a better position for making a successful transition to young adulthood.

\section{References}

Anderson, A. R., \& Henry, C. S. (1994). Family system characteristics and parental behaviors as predictors of adolescent substance use. Adolescence, 29, 405-420.

Ary, D. V., Tildesley, E., Hops, H., \& Andrews, J. (1993). The influence of parent, sibling, and peer modeling and attitudes on adolescent use of alcohol. The International Journal of the Addictions, 28, 853-880.

Brown, S. A., Tate, S. R., Vik, P. W., Haas, A. L., \& Aarons, G. A. (1999). Modeling of alcohol use mediates the effect of family history of alcoholism on adolescent alcohol expectancies. Experimental and Clinical Psychopharmacology, 7, 20-27.

Caspi, A., Bem, D. J., \& Elder, G. H. (1987). Moving against the world: Life-course patterns of explosive children. Developmental Psychology, 23, 308-313.

Charmaz, K. (1995). Grounded theory. In J. A. Smith, R. Harré, \& L. V. Langenhove (Eds.), Rethinking methods in psychology (pp. 27-49). Thousand Oaks, CA: Sage.

Elder, G. (1998). Life course and human development. In R. M. Lerner (Ed.), Handbook of child psychology, Vol. 1: Theoretical models of human development (pp. 939991). New York: John Wiley.

Fors, S. W., \& Rojek, D. G. (1991). A comparison of drug involvement between runaways and school youth. Journal of Drug Education, 21, 13-25.

Garland, A. F., Hough, R. L., Landsverk, J. A., McCabe, K. M., Yeh, M., Ganger, W. C., et al. (2000). Racial and ethnic variations in mental health care utilization among children in foster care. Children's Services: Social Policy, Research, and Practice, 3, 133-146. 
Ginzler, J. A., Cochran, B. N., Domenech-Rodriguez, M., Cauce, A. M., \& Whitbeck, L. B. (2003). Sequential progression of substance use among homeless youth: An empirical investigation of the gateway theory. Substance Use and Misuse, 38, 725-758.

Janus, M. D., Archambault, F. X., Brown, S. W., \& Welsh, L. A. (1995). Physical abuse in Canadian runaway adolescents. Child Abuse E Neglect, 19, 433-447.

Kandel, D. B., \& Andrews, K. (1987). Processes of adolescent socialization by parents and peers. The International Journal of the Addictions, 22, 319-342.

McCormack, A., Janus, M., \& Burgess, A. W. (1986). Runaway youths and sexual victimization: Gender differences in an adolescent runaway population. Child Abuse \& Neglect, 10, 387-395.

Powers, J. L., Eckenrode, J., \& Jaklitsch, B. (1990). Maltreatment among runaway and homeless youth. Child Abuse \& Neglect, 14, 87-98.

Tyler, K. A., \& Cauce, A. M. (2002). Perpetrators of early physical and sexual abuse among homeless and runaway adolescents. Child Abuse E Neglect, 26, 1261-1274.

Tyler, K. A., Hoyt, D. R., \& Whitbeck, L. B. (2000). The effects of early sexual abuse on later sexual victimization among female homeless and runaway youth. Journal of Interpersonal Violence, 15, 235-250.

Tyler, K. A., Hoyt, D. R., Whitbeck, L. B., \& Cauce, A. M. (2001). The impact of childhood sexual abuse on later sexual victimization among runaway youth. Journal of Research on Adolescence, 11, 151-176.

Whitbeck, L. B., \& Hoyt, D. R. (1999). Nowhere to grow: Homeless and runaway adolescents and their families. New York: Aldine de Gruyter.

Kimberly A. Tyler is an associate professor in sociology at the University of Nebraska-Lincoln. Her research interests include childhood abuse and neglect, high-risk behaviors, and mental health disorders among homeless and foster care youth and homeless emerging adults. 